\title{
SHOCK - WAVE- BOUNDARY- LAYER INTERACTION (SWBLI) AROUND OPEN FLAPS OF EXPERT CAPSULE AND THEIR CONSIDERATION ON HEAT AND MECHANICAL LOADS UNDER CRITICAL RE-ENTRY FLOW CONDITIONS
}

\author{
Dr. Ognjan Božicic ${ }^{(1)}$, Dr. José M. A. Longo ${ }^{(2)}$, Hannes Otto ${ }^{(3)}$ \\ German Aerospace Center (DLR), Lilienthalplatz 7, 38108 Braunschweig, Germany \\ ${ }^{(1)}$ Ognjan.Bozic@dlr.de, ${ }^{(2)}$ Jose.Longo@dlr.de, ${ }^{(3)}$ Hannes.Otto@dlr.de
}

\begin{abstract}
In the frame of EXPERT project DLR is proposing a flight experiment on shock-wave boundary-layer interaction (SWBLI) with shear-layer reattachment on control surfaces to improve our understanding about flap efficiency and heating due to high temperature 3D effects, radiation-cooling effects, transition, turbulence (unsteadiness) and strong viscous hypersonic interaction. The objective of the present work is applying CFD to estimate for the most critical flight condition the maximal aerothermodynamic loads on the capsule surface, with a special emphasis on the flaps and their surrounding. The very important questions to be answered for the design of the flaps are the determination of the magnitude and location of the maximum temperatures with respect to the vehicle surface and its corresponding internal structure. The CFD results for temperature, heat flux and surface pressure calculated for the selected critical flight condition show that the proposed concept for the instrumentation of both flaps and the capsule surfaces underneath the flaps is, generally in agreement with preliminary studies, but properties of TPS material on the flaps cavity flange should be enhanced to meet technical feasibility.
\end{abstract}

\section{Nomenclature}

\section{Symbol}

$\mathrm{q}_{\text {conv }}$ Quantity

Dimmension SI

$q_{\text {cond }}$ heat flux due convection heat flux due conduction \section{$\mathrm{W} / \mathrm{m}^{2}$}

$\mathrm{W} / \mathrm{m}^{2}$

$\mathrm{q}_{\mathrm{r} 13}$ heat flux due radiation between points 1 and $3 \quad \mathrm{~W} / \mathrm{m}^{2}$

F geometrical factor, which take in account radiation from PT1 in all direction beyond the flap -

\section{$\mathrm{H}$} altitude

Ma Mach number

$\mathrm{V}_{\mathrm{oo}} \quad$ velocity

$\mathrm{t}$ time

$\varepsilon_{1}$

variable fictive emission coefficient at cavity point 1

$\mathrm{m}$ variable fictive emission coefficient at mirrored flaps backside point 3 (free radiation) at cavity pt. 1 -

Stefan-Boltzmann-Constant $\sigma=5.669710^{8}$

\section{List of Acronyms}

A/D Analog/Digital

$\mathrm{BC}$

CFD

CMC

DKR

ESA

EXPERT

FCW

FEI

NCW

$\mathrm{NE}$

NS

ODS

P.I.

PCW

PDR

PG

RA

SWBLI

TPS

Navier-Stokes

Perfect Gas

Interaction
Boundary Condition(s)

Computational Fluid-Dynamics

Ceramic Matrix Composite

Detra-Kemp-Riddell

European Space Agency

European eXPErimental

Re-entry Testbed

Fully Catalytic Wall

Flexible External Insulation

Non- Catalytic Wall

Non-Equilibrium

Oxide-dispersion strengthend

Principal Investigators

Partially Catalytic Wall

Preliminary Design Review

Radiation-adiabatic conditions

Shock-Wave Boundary-Layer

Thermal Protection System 


\section{INTRODUCTION}

The primary objective of EXPERT is to provide a test-bed for the validation of aerothermodynamics models, codes and ground test facilities in a representative flight environment, to improve the understanding of issues related to analysis, testing and extrapolation to flight. Various candidate shapes were analysed and traded-off [3]. The retained solution consists of a low-cost reentry capsule (mass $360 \mathrm{~kg}$ ) with conical shape and blunt-nose, to be launched by a Russian submarine - based VOLNA sub-orbital launcher (which employs the R-29R missile). EXPERT is designed for sub-orbital flights with a re-entry velocity range from 5 to $7 \mathrm{~km} / \mathrm{sec}$. Three recurring flights, with dedicated flight units are intended. The foreseen landing site is the Russian military base in the Kamchatka peninsula.

The experiments (defined as payloads 1-16) officially involved in the EXPERT program, are reported in Table 1. All these experiments are focused to improve, using last state of development instrumentation, the understanding of the following critical aero-thermodynamics phenomena: transition, catalysis, real gas effects on SFBLI, micro-aerothermodynamics, shock layer chemistry and blackout [1].

In the frame of EXPERT project the German Aerospace (DLR) is proposing a flight experiment on shock-wave boundary-layer interaction (SWBLI) with shear-layer reattachment on control surfaces (Payload \#6) to improve our understanding about flap efficiency and heating due to high temperature 3D effects, radiation-cooling effects, transition, turbulence (unsteadiness) and strong viscous hypersonic interaction. The interest to resolve this phenomena around open flaps lies almost in the complete continuous reentry flight regime for altitude range $90 \mathrm{~km}<\mathrm{H}<20 \mathrm{~km}$, with emphasis in the $70 \mathrm{~km}<\mathrm{H}<50 \mathrm{~km}$ altitude range.

In the pre-flight phase one of the main issues related to DLR's payload \#6 is concentrated to estimate realistic thermal loads on the capsule surface under extreme flight conditions, with especial emphasis on the open flaps and their surrounding by means of CFD. Estimated heat loads and surface temperatures should be below permitted limits for structure material strength. Also, it must be assured that sensors and measurement equipment are working under protected thermal environment. Connected with this requirements it is important to clear how the characteristic length, form and position of subsonic vortices as a part of the SWBLI affects the heat transfer on the open flaps ramp and their environments.

\section{DESIGN DESCRIPTION OF EXPERT CAPSULE}

The EXPERT capsule shape is composed of few geometrical elements: an ellipsoidal blunt nose, a conical body, a clothoid ellipse-cone junction and four flat sides with four fixed flaps, two opens and two closed ones (Fig. 1). The external lateral thermal shield which cover the conical body consist of four curved corner panels and four triangular panels [2]. The thermal protection system include four main areas: a C/SiC nose cap, metallic TPS on the conical sides, Flexible External Insulation (FEI) on the rear side and four ceramic flaps. The TPS surface is instrumented to allow reconstruction the flow conditions after flight, as part of the 16 experiments. The nose cap, the external shield and the four flaps are exposed to high aerodynamic drag and high heat loads.

The design concept for the open flaps comprises a fully integral manufactured control surface with additional stiffening rib and flanks to meet the first mode frequency requirement with minimum necessary mass (Fig. 2). The concept developed by MT Aerospace (former MAN TE) [6], incorporates a hinge seal mounting provision, harness and flap support lead-through as well as two hinge support interfaces and four fixations for assembling a $\mathrm{C} / \mathrm{SiC}$ cover cavity-plate underneath the flap, to the cold structure. Between cover cavityplate and cold structure, a flat $\mathrm{Al}_{2} \mathrm{O}_{3}$ insulation was foreseen. However, the actual system design envisaged a flap surrounding and covers cavityplate based on PM1000 TPS material (Fig. 3).

The integration of the open flap instrumentation corresponds to the Wind Tunnel Branch of the Institute of Aerodynamics and Flow Technology of DLR. The integration requires clear interfaces to the flap and to the vehicle itself. Figure 4 shows the sensors and their interfaces to the flap, which are critical with respect to thermal, mechanical and dynamic loads. Thermocouples will be mounted to the flap rear surface with high tem- 
perature adhesives. The pressure ports are fixed using a technique with combined screw and port functions. Both pressure tubes and thermocouple wires are supported with a $\mathrm{C} / \mathrm{SiC}$ plates before passing the harness fixation. The micro-pyrometer optical head and heat flux sensors are mounted on a sensor assembly plate under the cavity. The optical window of the pyrometer is integrated into the cavity. The pyrometer itself and pressure gauges are mounted to the electronic box, which provides final analog signals to the $A / D$ converter of the main data acquisition system of the mission (Fig. 5).

All the computations presented here refer to the EXPERT 4.2 geometry. Such geometry is characterized by the main properties reported in fig. 1. The main difference between the last geometry configuration $4.4 \mathrm{~b}$ w.r.t. analyzed 4.2 is that the bluntness has been increased (from 550 to 600 $\mathrm{mm}$ ) and the angles of the flat faces have been slightly decreased (from 9 to $8.35 \mathrm{deg}$ ). The above described geometrical changes have only a slight impact on Payload \# 6 with respect the effective incidence of the flap, i.e. a $0.65 \mathrm{deg}$ reduction, which shall alleviate a little the thermal environment of the flap.

\section{MODELING TOOLS}

\subsection{Flow solver}

The flow solver used in this work is the DLR TAU code [9]. The TAU code is a finite volume Euler/Navier-Stokes solver which can use structured, unstructured and hybrid meshes and has already been applied to the study of various configurations. The Reynolds averaged NavierStokes (RANS) equations are discretised by a finite volume technique using tetrahedras and prisms.

Prismatic elements are used for boundary layer region while the tetrahedral ones are used in inviscid flow regions. As numerical scheme the AUSMDV second order upwind scheme [5] with MUSCL extrapolation is used. For time discretisation, including local time stepping, a three dimensional Runge-Kutta as well as an implicit, approximately factored LU-SGS scheme is implemented. For acceleration multigrid and explicit residual smoothing are available. Furthermore, parallel computing is possible via domain splitting and MPI communication. The internal data storage is based on an efficient edge-data structure, using the NETCDF format. In the presented RANS cases the one-equation Spalart-Allmaras (SA) [13] with modifications done by Edward and Chandra [8] is used

The chemical non equilibrium model incorporated in TAU-code for real gas calculations has following properties [12]. For temperature dependent reaction rates the modified approach of Arrhenius is used. For the presented work a 5 species mixture of $\mathrm{N}_{2}, \mathrm{O}_{2}, \mathrm{~N}, \mathrm{O}$ and $\mathrm{NO}$ with 17 reactions is used. The implemented reaction model is described by Park [7]. The thermodynamic data for the pure species are taken from Bottin [5], the transport properties from Gupta [11]. Vibrational excitation is assumed to be in equilibrium with translational and rotational excitation (one temperature model). Mixture properties for viscosity are computed using Wilke's rule [17]. The thermal conductivity is computed using the rule of Zipperer and Herning [18] with constant Schmidt number.

\subsection{Numerical discretization}

Flow simulations are done for a half configuration. To generate the grids from the CATIA drawings data, the commercial CENTAUR mesh generator is used. The Navier-Stokes mesh has 24 prismatic layers in the boundary layer. The height of the first cell is selected in such way, that $y+<1$ for all viscous cases. Figures 6-7 are views of the grid used. The reference grid for the computed cases is the same and has totally 20.75 mill. elements; from that number approx. $27 \%$ are prism elements within the boundary layer. In flow field areas with high pressure-, high density- and high velocity gradients the grid is several times adapted increasing the number of prismatic /tetrahedral elements up to 36 mil. elements.

\subsection{Heat conduction and radiation}

Most of the EXPERT capsule surface panels are able to radiate unhindered in free environment but between the open flaps and the cavity underneath the flaps, a direct visibility situation between surfaces exists (Fig. 9). The smaller the distance between the visible surfaces, the stronger the obstruction is for free radiation and therefore the smaller the effective emissivity coefficient. That 
circumstance increases radiation heating between surfaces. Hence, the surface temperature of the flap leeward side and of the cavity wall underneath the flap shall be computed accounting for the surface view factors. Finally, an additional temperature increase is caused due to heat conduction through the material; in this case between flap windward and leeward side. This heat conduction additionally intensifies radiation between flaps and surface cavity underneath the flap.

It turns out, it is a complex three-dimensional problem which to be properly solved, requires coupling of flow, structure and gas radiation under non equilibrium gas conditions but such solutions demand larger computer resources not available in a preliminary-design phase of the project. Hence, to obtain the corrected wall temperature distribution at the flaps and cavity underneath the flaps, accounting for back radiation and heat conduction, the following procedure is used. First, CFD simulations are carried out assuming radiation adiabatic walls with constant emissivity coefficients. For selected points of the configuration surface (usually of interest are hot spots) a heat balance equation is satisfied accounting for radiation, convection, heating due to direct visibility with glowing surfaces and conduction through the material as is expresed by the Eqs. 1-2 for the surface temperature $T_{1}$ :

$$
\begin{gathered}
\varepsilon_{13}=\frac{1}{\frac{1}{\varepsilon_{1}}+\frac{1}{\varepsilon_{3}}-1} \\
T_{1}=\left[\frac{\varepsilon_{13} \cdot T_{3}^{4}}{\varepsilon_{13}+F \cdot \varepsilon_{R}}+\frac{\left(q_{\text {conv }}-q_{\text {cond }}\right)}{\left(\varepsilon_{13}+F \cdot \varepsilon_{R}\right) \cdot \sigma}\right]^{0.25}
\end{gathered}
$$

Figure 8 shows an example of the heat flux balance here described. As input for the temperature calculation are necessary to know: convective flux (result of flow calculation with TAU), variable effective emissivity coefficients and temperature conduction from the windward to the leeward flap side calculated on the basis of 1D model from J. C. Lengrand by CNRS [4]. The wall is approximated in this case with a semi-infinite thickness and the temperature profiles are taken as parabolic. Furthermore, to obtain the effective emissivity factors, a separate model for flaps and cavity are used (Fig. 8). For this model a special structured surface mesh of medium size with 2000 panels is generated and the visibility coefficients and the variable effective emissivity coefficients for every surface element are calculated with the program "GETHRA" [19].

\section{FLOW CONDITIONS}

The computations are performed for the EXPERT trajectory point with maximum heat flux. The selected flow condition is Mach number 16.3, velocity $6.0 \mathrm{~km} / \mathrm{s}$, altitude $37.32 \mathrm{~km}$ which corresponds to the worse case for mission $2.2 \mathrm{a}$. The reference trajectory is shown in Fig. 10. Two CFD solutions are realized. The first one delivers the lowest heat loads and wall temperatures (case 1) since it has been done assuming real gas, chemical non-equilibrium, laminar flow, noncatalytic radiation adiabatic walls with constant emissivity coefficients $\varepsilon=0.85$. The second solution (case 2) accounts for the highest heat loads and wall temperatures, i.e. real gas, chemical non-equilibrium, turbulent flow, full catalytic radiation adiabatic walls with constant emissivity coefficients $\varepsilon=0.85$.

The aerothermal environment in terms of temperature and heat flux at different points of the reentry trajectory is derived of that computed for the capsule stagnation point by means of the Detra-Kemp-Riddel equation. Knowing the ratio between the Detra-Kemp-Riddel stagnation point temperature and heat flux values and the resulting from the CFD simulations at the trajectory point $\mathrm{Ma}=16.3, \mathrm{H}=37320 \mathrm{~m}$, it is possible to establish the aerothermal environment for the complete capsule along the whole trajectory.

Finally, for the above mentioned heat balance the heat capacity of the cavity-plate underneath the flap is neglected. This effect was accounted in earlier works but the change is insignificant.

\section{RESULTS}

The SWBLI phenomenon here numerically investigated is related to the control-surface (flaps) problem. In general, the interaction on the flap is an Edney type VI interaction. In the flow field it is possible to recognize three shocks: the separation shock, induced by the flow deflection due to the viscous regime; the inner reattachment shock, 
induced by the final reflection of the flow at the ramp; a single stronger outer shock formed when first two shocks meet each other in the triple point T (Fig. 13).

Generally the upstream influence of the ramp on the flap depend upon of ramp angle; flow Mach number and Reynolds number; boundary layer state (laminar/turbulent); gas properties and gas state (perfect gas, equilibrium state or real gas conditions); atmospheric conditions (flight altitude) and surface temperature respectively heat loads on the ramp. The SWBLI influence decreases with increasing Mach number and increases with increasing ramp angle. Further, the influence of gas state under real gas condition must be proved related to the Mach number values in the flow and surface temperature.

For the two computed cases (lowest loads for laminar flow with non catalytic walls and highest loads for turbulent flow with full catalytic walls) the SWBLI shows the classical features known from fluid mechanic theory (Figs. 11-12). In general the laminar and turbulent flows are affected on the same way, the interaction being weaker for turbulent flows. The length of the separation region $L_{S R}$ (between separation and reattachment point) is a measure of the SWBLI strength. In the laminar flow was founded $L_{S R}=224 \mathrm{~mm}$, which is 5.6 times larger then for turbulent flow case (Figs. 13-14). This numerical result should be confirmed in the future due to a more comprehensive numerical study with different grid refinements.

From the two computed solutions, five characteristic points (PT) are considered (Figs. 19-20) for the present analysis:

PT1 - on the cavity wall underneath the flap, hot spot with maximum wall temperature,

PT2 - mirrored point of PT1 on the windward side of the flap,

PT3 - mirrored point of PT1 on the leeward side of the flap, backward,

PT4 - on the integral flange of the cavity-supportlead, hot spot with maximum temperature,

PT5 - on the windward side of the flap reference; hot spot with absolute flap maximum temperature.
Figures 15-18 show the aerothermal environments resulting for the five selected hot spots. Figure 15 shows for case 1 (laminar flow, CNE NCW) that the maximum temperature at $T_{1}$ is $133 \mathrm{~K}$ higher than the radiation adiabatic conditions without corrections, but still under the ODS iron based super alloy PM1000 limits. Similar situation is found for the heat loads. More critical is PT4 which for case 1 exhibit during more than 40 seconds a surface temperature and heat flux over the limits for high creep strength (Fig.16). Indeed, the temperature in PT4 is clearly over the melting conditions for the selected material.

Under case 2 computational conditions (turbulent flow, CNE - FCW), Fig. 17 shows that the consequences for the cavity-TPS material are much more serious. While the heat flux is bellow the limit of $225 \mathrm{~kW} / \mathrm{m}^{2}$ (Fig. 18), the temperature in hot spot PT1 is during 35 s over the permitted limits for high creep strength. At hot spot PT4 during $70 \mathrm{~s}$ the temperature is over the temperature for high creep strength and more than 40s over the melting point for PM1000. Also the heat flux in PT4 is approx. $60 \mathrm{~s}$ largely over the heat flux limit, almost a factor 4 . The results suggest that also assuming partial catalytic walls it may be not possible to guarantee the TPS material will withstand the harsh aerothermal condition and mission success.

\section{CONCLUSION}

In the aerothermodynamic analysis for EXPERT capsule the priority has been given to reference mission $2(6 \mathrm{Km} / \mathrm{s}$ re-entry speed). The reference trajectory $2.2 \mathrm{~b}$ shows external heat flux and thermo-mechanical loads, which are severe with respect to thermal protection material characteristics and performances.

The analysis was concentrated at the open flaps and their environments, which is important for the successes of measurement equipments foreseen for Payload \#6, but also for the complete mission. The output of the aerothermodynamic analysis of the flaps, which includes fluxes under real gas conditions with thermo-chemistry, catalysis effects and their time variation, basically led to a requirement for change the selected TPS architecture in the open flaps cavity. Indeed, the selected material doesn't meet today the mission requirements. 


\section{References}

1. Massobrio F., Caporicci M., Serpico M., Development Status of EXPERT, the European eXPErimental Re-entry Testbed, AIAA/ CIRA $13^{\text {th }}$ International Space Planes and Hypersonics Systems and Technologies, May 2005, Capua, Italy, AIAA 2005-3446

2. Gammartota A., Development of a Structural Design for a New Atmospheric Re-entry Vehicle: Expert a Forerunner, AIAA/CIRA 13th International Space Planes and Hypersonics Systems and Technologies, May 2005, Capua, Italy, AIAA 2005-3309

3. Walpot L., Ottens H., FESART/EXPERT Aerodynamic and Aerothermodynamic analysis of REV and KHEOPS configurations, Techn. Rep.TOS-MPA/2718/LW, ESA-ESTEC, May 2003

4. Bonnet A.- Luneau J., Théories de la Dynamique des Fluides - Éditions Cépaduès - Sept. $1989-544 p$

5. Bottin, B., Aerothermodynamic Model of an Inductively-Coupled Plasma Wind Tunnel, Dissertation, Université de Liège, 1999.

6. Park, C., Review of Chemical-Kinetic Problems of Future NASA Missions, I: Earth Entries, Journal of Thermophysics and Heat Transfer, 1993

7. Gülhan A., Handrick K., Longo J. M. A., EXPERT - Phase B: Development of Flight Test Measurement (FMT) Technolgies for InFlight Aerothermodynamics Research; PAYLOAD \#6: Open Flaps SWBLI Final Report, Report DLR - Inst. Of Aerodynamics and Flow Technology, IB-124-2004/23

8. Edwards J. R., Chandra S., Comparison of Eddy Viscosity-Transport Turbulence Models for Three-Dimensional, Shock-Separated Flowfields, AIAA Journal, 34(4), 1996.

9. Gerhold T., Friedrich O., Evans J., Galle M, Calculation of Complex Three-Dimensional Configurations Employing the DLR-TAUCode, AIAA 97-0167, 1997
10. Brück S., Radespiel R., Longo J. M. A., Comparison of the Nonequilibrium Flows past a Simplified Space-Shuttle Configuration, 35th Aerospace Sciences Meeting \& Exhibit, Jan. 6-10,1997, Reno, NV, USA

11. Gupta R. N., Yos J. M., Thompson R. A., Lee K-P., A Review of Reaction Rates and Thermodynamic and Transport Properties for an 11- Species Air Model for Chemical and Thermal Nonequilibrium Calculations to 30000 K. Reference Publication 1232, NASA, USA, 1990

12. Hannemann V., Numerische Simulation von Stoß-Stoß-Wechselwirkungen unter Berücksichtigung von chemischen und thermischen Nichtgleichgewichtseffekten, DLR, Institut für Aerodynamik und Strömungstechnik, Forschungsbericht 97-07, Göttingen, 1997

13. Spalart P.R., Allmaras S.R., A One-Equation Turbulence Model for aerodynamic Flows, AIAA 92-0439, 1992.

15. Wada Y., Liou M. S., A Flux Splitting Scheme with High-Resolution and Robustness for discontinuities, AIAA 94-0083, 1994.

16. Wilcox, D. C., Turbulence Modeling for CFD, DCW Industries, Inc., 1993.

17. Wilke C. R., A Viscosity Equation for Gas Mixtures, The Journal of Chemical Physics, 18(4), 1950, pp. 517-519.

18. Zipperer L., Herning F., Beitrag zur Berechnung der Zähigkeit technischer Gasgemische aus den Zähigkeiten der Einzelbestandteile. Das Gas- und Wasserfach, 4(49), 1936.

19. Höld, R., Fornasier, L., Investigation of thermal loads on hypersonic vehicles with emphis on surface radiation effects, DASALME12-S-PUB-543, AIAA Congress Anaheim, 1994 
Table 1. Payload objectives and instrumentation

\begin{tabular}{|c|c|c|}
\hline Payload & Objective: & P.I. \\
\hline $\mathrm{P} 1$ & $\begin{array}{l}\text { FADS - Indirect measurement of the free stream speed vector and free stream } \\
\text { density during atmospheric portion of the flight. }\end{array}$ & DLR \\
\hline $\mathrm{P} 2$ & Measurement of stagnation and cone heating (temperatures and heat fluxes). & DLR \\
\hline P3 & $\begin{array}{l}\text { Measurements of the gas species concentration close to the surface and of } \\
\text { surface heat flux }\end{array}$ & EADS \\
\hline $\mathrm{P} 4$ & Experiment coupled with P5 & --------- \\
\hline P5 & $\begin{array}{l}\text { Physical understanding of natural and roughness-induced } \\
\text { boundary-layer transition during the re-entry atmospheric flight. }\end{array}$ & CIRA \\
\hline P6 & $\begin{array}{l}\text { Physical understanding of shock-wave boundary-layer Inter- } \\
\text { action (SWBLI) with flow reattachment on control surfaces during the re-entry } \\
\text { atmospheric flight. Instrumentation: Thermocouples, Micropyrometer and } \\
\text { combined heat fluxes-pressures sensors. }\end{array}$ & DLR \\
\hline P7 & $\begin{array}{l}\text { Measurement of Flight SWBLI effects on flat faces }(20 \mathrm{deg}) \text {, and } \\
\text { design of a representative experiment in the CIRA Scirocco Facility. }\end{array}$ & CIRA \\
\hline P8 & $\begin{array}{l}\text { Closed flaps - In-Flight Measurements of pressures and heat fluxes on closed } \\
\text { flaps by using infrared and temperature sensitive paint techniques shielded } \\
\text { inside the closed flaps. }\end{array}$ & HTS \\
\hline P9 & $\begin{array}{l}\text { Non-intrusive measurement of the shock-layer chemistry, } \\
\text { through electron beam fluorescence (EBF) techniques. }\end{array}$ & ONERA \\
\hline P10 & $\begin{array}{l}\text { Non-intrusive measurement of the shock-layer chemistry, } \\
\text { through UV-Visible-IR Spectroscopic measurements (RESPECT ). }\end{array}$ & IRS \\
\hline $\mathrm{P} 11$ & $\begin{array}{l}\text { Measurement of the boundary layer characteristics and electron } \\
\text { density profiles, through Pitot and Langmuir probes. }\end{array}$ & VKI \\
\hline P12 & $\begin{array}{l}\text { Measurements of base-flow characteristics and RCS } \\
\text { interactions, through pressure sensors and thermocouples }\end{array}$ & Centrospatio \\
\hline P13 & $\begin{array}{l}\text { Slip-flow characteristics, through sensitive skin friction } \\
\text { measurements }\end{array}$ & HTG \\
\hline $\mathrm{P} 14$ & $\begin{array}{l}\text { Measurements of blackout, using reflectometers (embedded } \\
\text { antennas). }\end{array}$ & Polit. of Turin \\
\hline P15 & $\begin{array}{l}\text { Test of a winglet made of an UHTC leading edge attached to a } \\
\text { ODS alloy support. }\end{array}$ & CIRA \\
\hline P16 & Test of an enhanced radiation cooling system & TU Delft \\
\hline
\end{tabular}

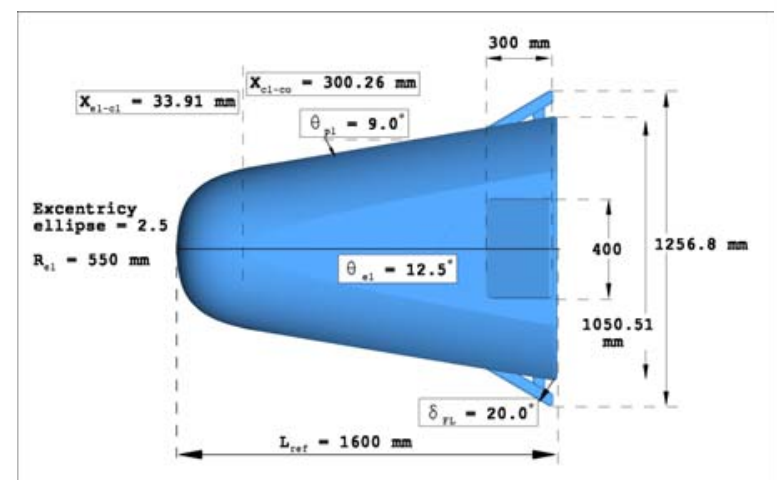

Fig. 1: EXPERT capsule design - revision 4.2

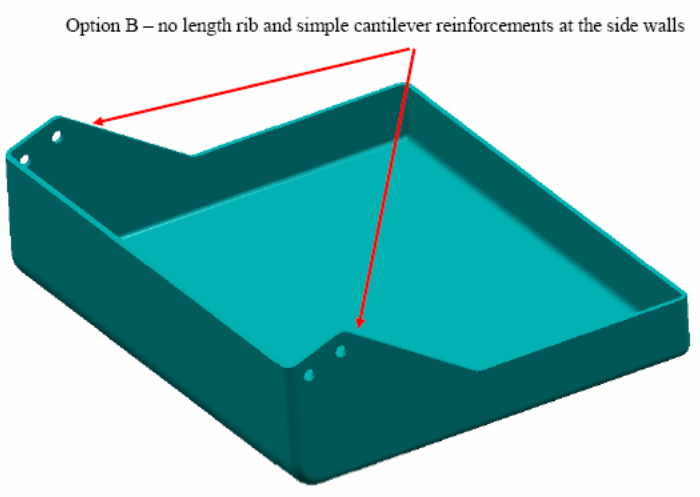

Fig. 2: Open Flap - Design MT Aerospace. 


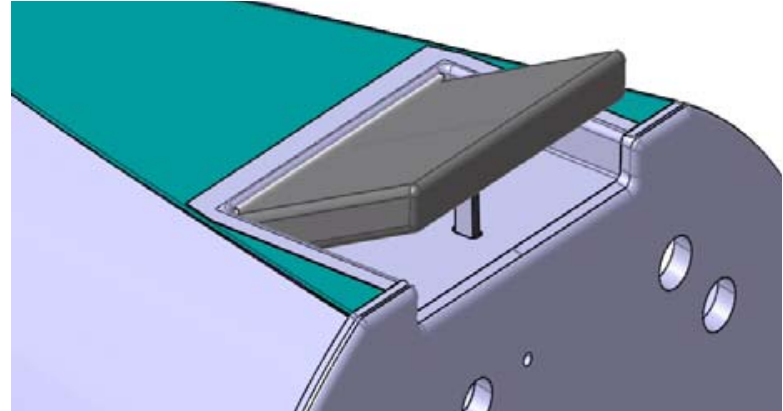

Fig. 3: Open Flap finally assembled (MT Aerospace courtesy).

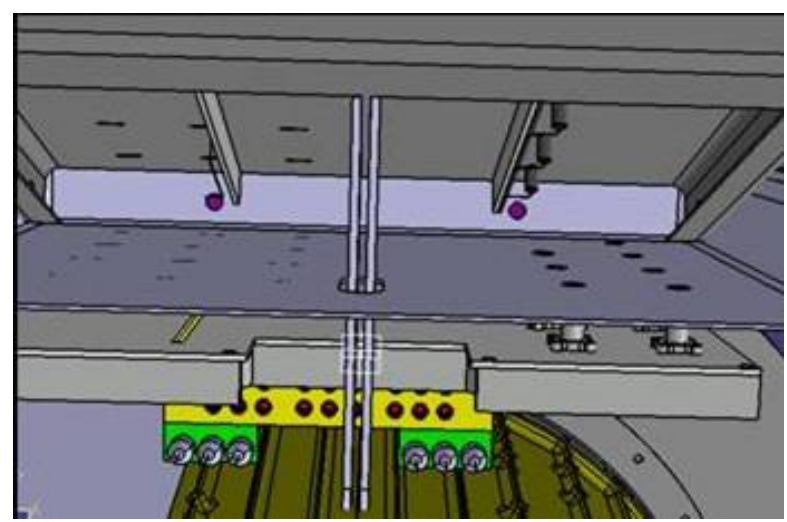

Fig. 4: Bottom view of the open flap with integrated sensors (DLR AS-WK courtesy).

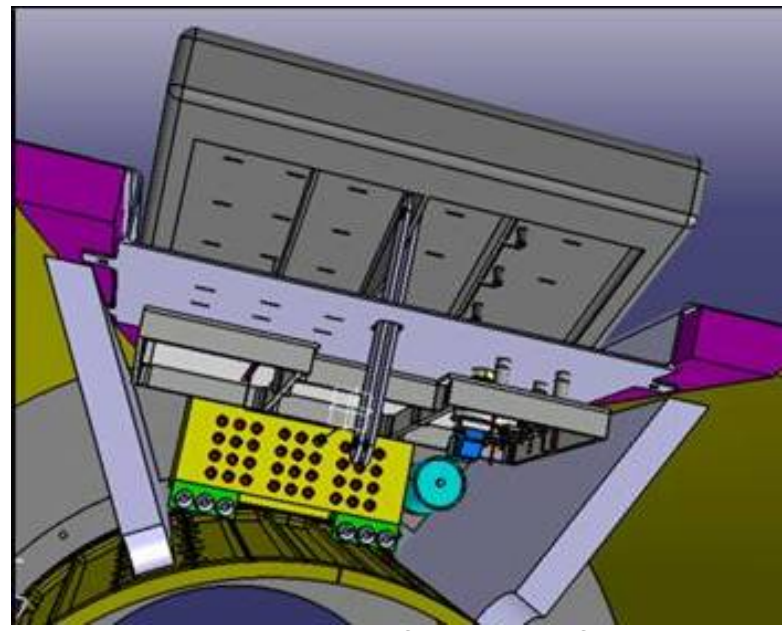

Fig 5: Rear side view of the open flaps with integrated sensors (DLR-AS-WK courtesy).

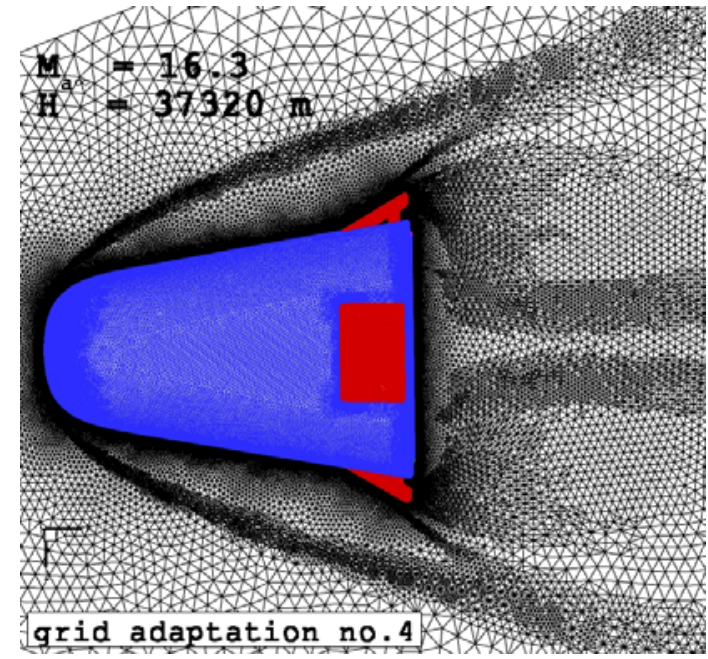

Fig. 6: Unstructured hybrid grid after $4^{\text {th }}$ adaptations.

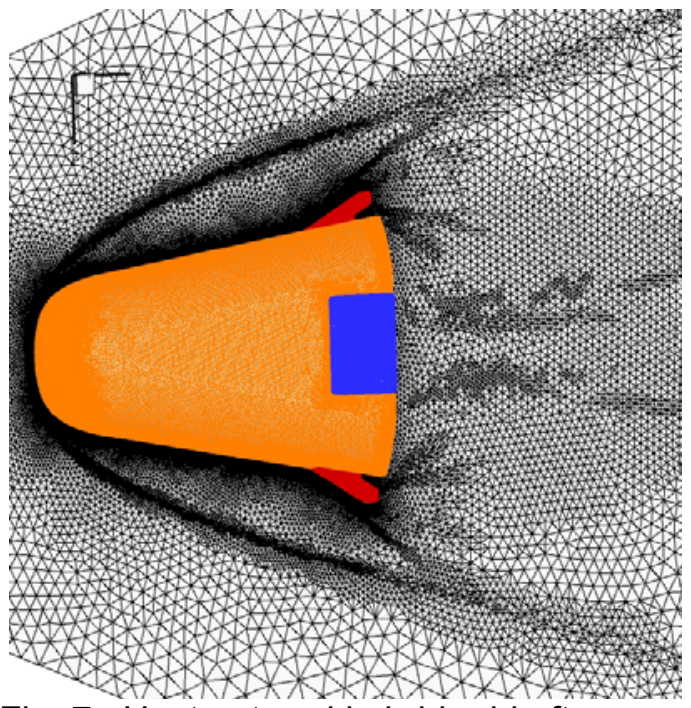

Fig. 7: Unstructured hybrid grid after $5^{\text {th }}$ adaptations.

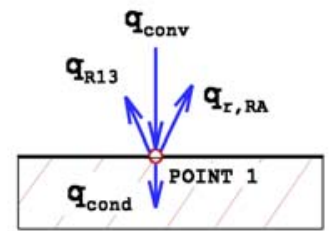

Fig. 8: Heat balance for point 1. 


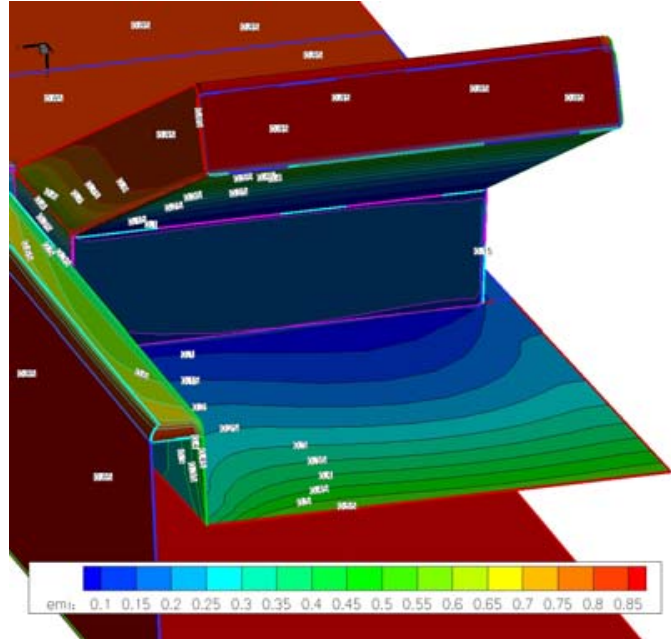

Fig 9: Calculated variable effective emissivity coefficients.

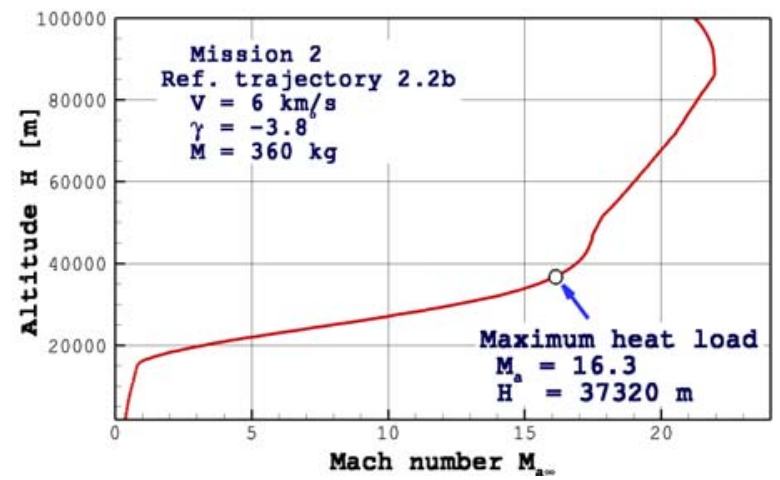

Fig. 10: Reference trajectory $2.2 \mathrm{~b}$

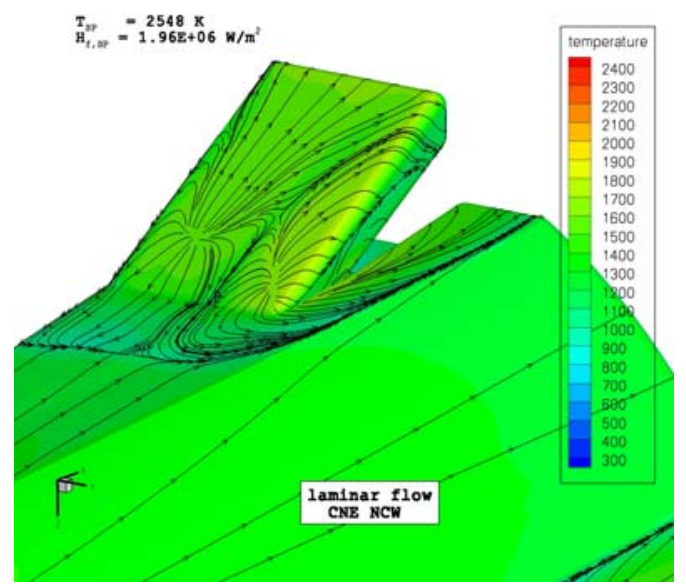

Fig. 11: Temperature contours and streamlines for laminar flow, CNE - NCW.

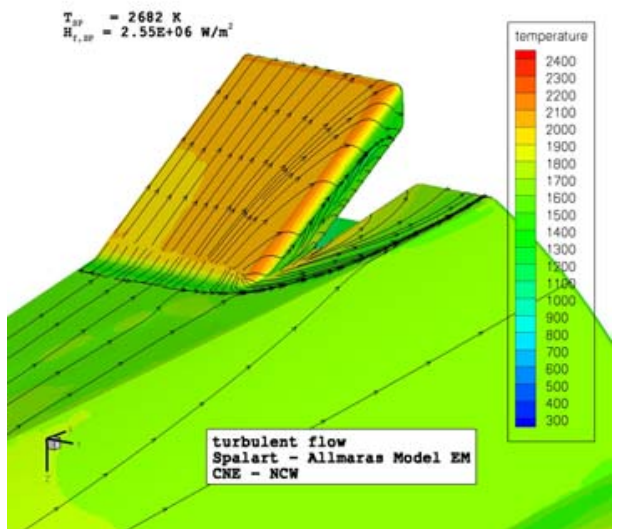

Fig. 12: Temperature contours and streamlines for turbulent flow, CNE - FCW.

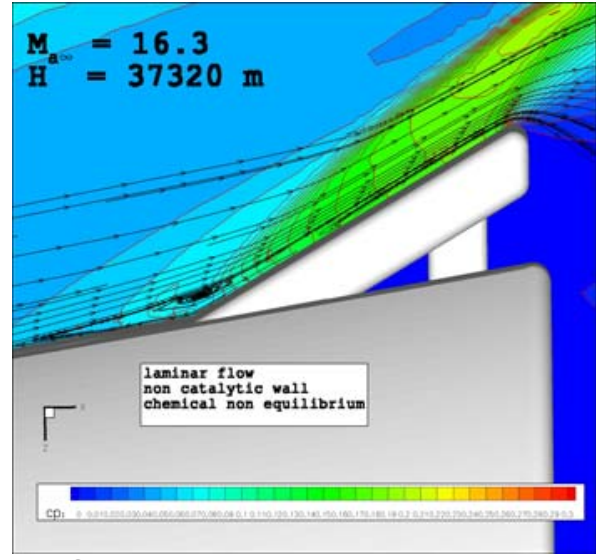

Fig. 13: Cp contours and streamlines for laminar flow, CNE - NCW

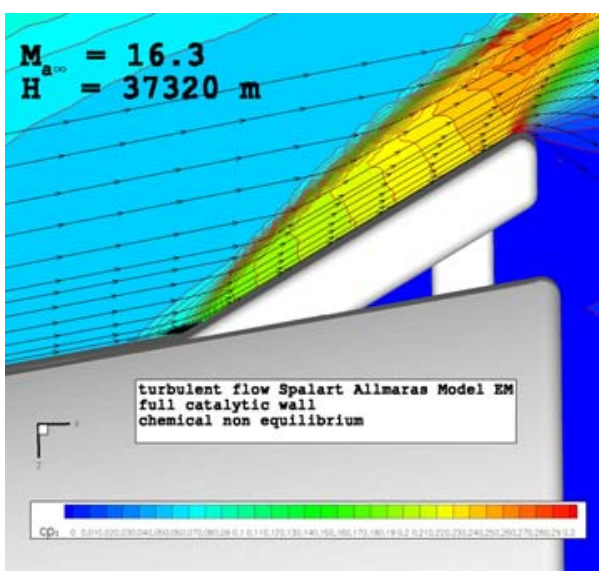

Fig. 14: $\mathrm{Cp}$ distribution and streamlines for turbulent flow, CNE - FCW 


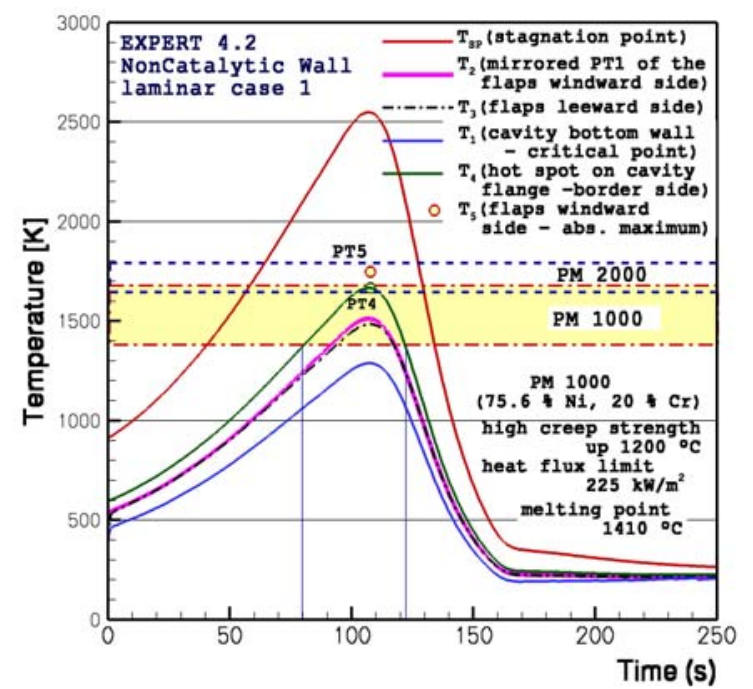

Fig. 15: Time extrapolation for temperature, case 1 , in different surface points.

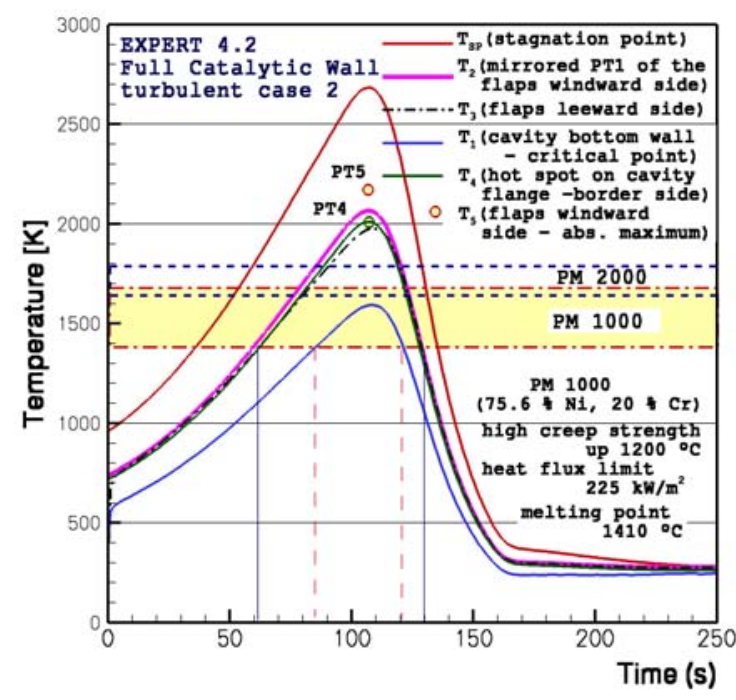

Fig. 17: Time extrapolation for temperature, case 2, in different surface points.

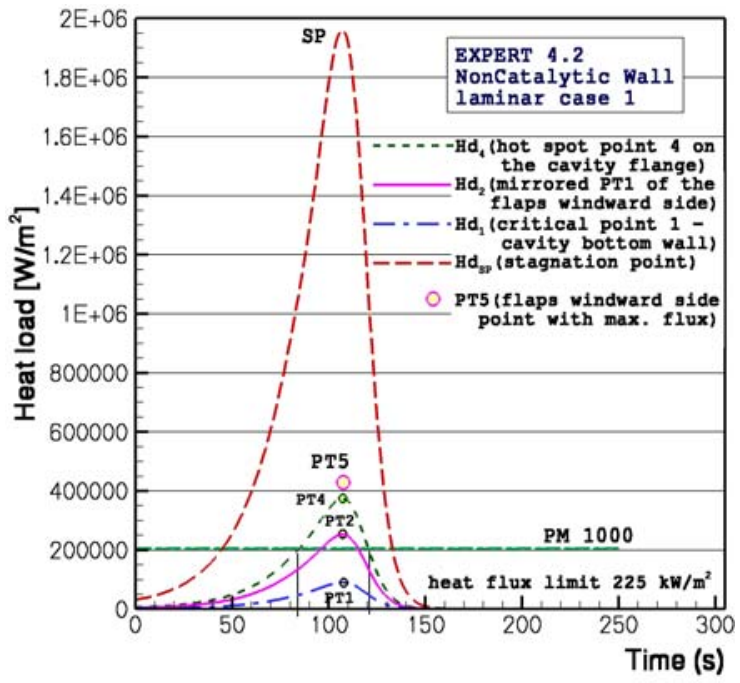

Fig. 16: Time extrapolation for heat flux, case 1 , in different surface points.

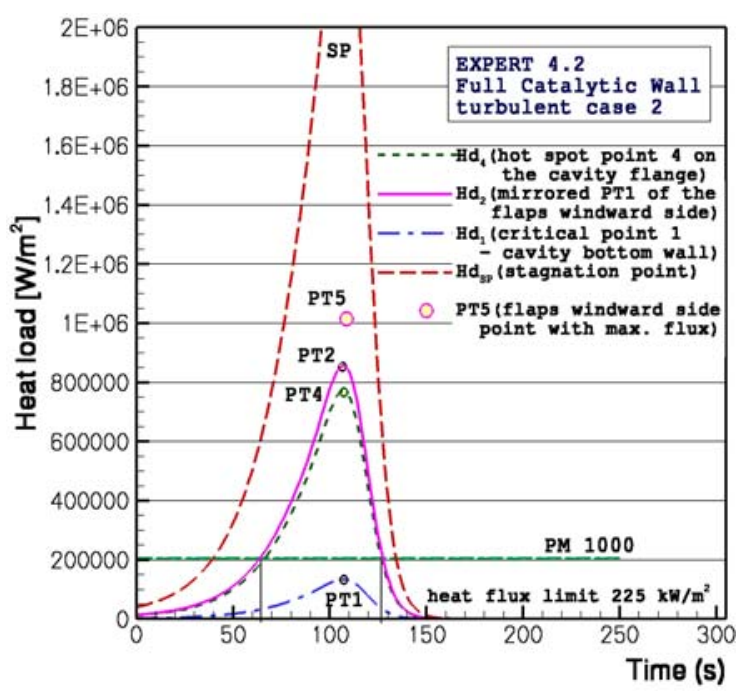

Fig. 18: Time extrapolation for heat flux, case 2, in different surface points. 

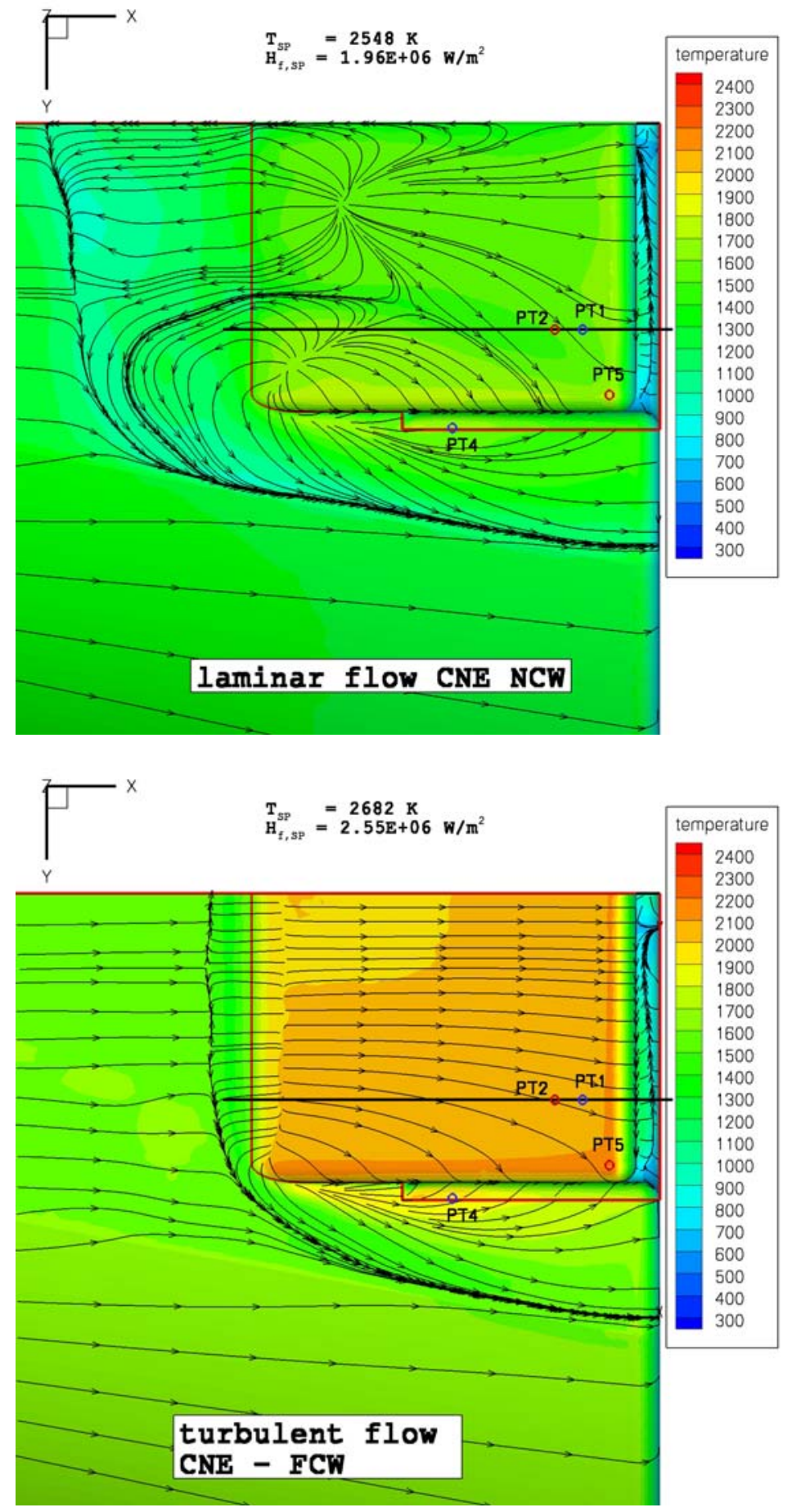

Fig.19: Temperature contours and streamlines for laminar flow, CNE - NCW (top view on the windward side of flap). Also can be recognized the location of points 2, 4 and 5. Location of point 1 is underneath of flap; on the cavity bottom surface.
Fig. 20: Temperature contours and streamlines for turbulent flow, CNE - FCW (top view on the windward side of flap). Also can be recognized the location of points 2, 4 and 5. Location of point 1 is underneath of flap; on the cavity bottom surface. 